\title{
Successful oral desensitization with crizotinib after crizotinib-induced hepatitis in an anaplastic lymphoma kinase-rearranged non-small-cell lung cancer patient: A case report
}

\author{
YUTO YASUDA $^{1}$, YASUYO NISHIKAWA ${ }^{2}$, YUICHI SAKAMORI ${ }^{1}$, MAKOTO TERAO $^{3}$, \\ KENTARO HASHIMOTO ${ }^{4}$, TOMOKO FUNAZO ${ }^{1}$, TAKASHI NOMIZO ${ }^{1}$, TAKAHIRO TSUII ${ }^{1}$, \\ HIRONORI YOSHIDA ${ }^{1}$, HIROKI NAGAI ${ }^{1}$, HIROAKI OZASA ${ }^{1}$, TOYOHIRO HIRAI ${ }^{1}$ and YOUNG HAK KIM ${ }^{1}$ \\ ${ }^{1}$ Department of Respiratory Medicine, Kyoto University Graduate School of Medicine, Kyoto 606-8507; \\ ${ }^{2}$ Department of Surgery, Gastrointestinal Center, Kyoto-Katsura Hospital, Kyoto 615-8256; ${ }^{3}$ Department \\ of Clinical Pharmacology and Therapeutics, Kyoto University Hospital, Kyoto 606-8507; ${ }^{4}$ Department \\ of Respiratory Medicine, Shiga Medical Center for Adults, Moriyama, Shiga 524-0022, Japan
}

Received February 9, 2017; Accepted April 13, 2017

DOI: $10.3892 / \mathrm{mco} .2017 .1310$

\begin{abstract}
Crizotinib is one of the molecularly-targeted agents targeted against anaplastic lymphoma kinase (ALK)-rearranged non-small-cell lung cancer (NSCLC). Although its effects appear to be promising, crizotinib may cause adverse effects in patients with ALK-rearranged NSCLC. Hepatic laboratory abnormalities are frequently observed with crizotinib and treatment discontinuation is occasionally required. We herein report the case of a 51-year-old woman diagnosed with relapsed ALK-rearranged NSCLC, who received crizotinib as second-line systemic chemotherapy. After 17 days of crizotinib therapy, the patient developed grade $>3$ hepatotoxicity. Treatment discontinuation improved the laboratory abnormalities and fifth-line oral desensitization with crizotinib achieved successful response without hepatotoxicity. Therefore, oral desensitization with crizotinib may be a viable option following crizotinib-induced hepatitis.
\end{abstract}

\section{Introduction}

Lung cancer is the leading cause of cancer-related mortality worldwide. Anaplastic lymphoma kinase (ALK) rearrangement mutation was observed in 3-5\% of lung adenocarcinomas from patients in East Asia (1). Crizotinib, which is the first

Correspondence to: Dr Yuichi Sakamori, Department of Respiratory Medicine, Kyoto University Graduate School of Medicine, 54 Shogoin-kawaracho, Sakyo-ku, Kyoto 606-8507, Japan

E-mail: sakemori@kuhp.kyoto-u.ac.jp

Key words: desensitization, anaplastic lymphoma kinase, crizotinib, non-small-cell lung cancer, hepatitis agent against lung cancer with ALK rearrangement mutation, has been found to be superior to standard first-line cytotoxic chemotherapy in the first-line setting (2). Crizotinib is occasionally associated with drug-induced hepatitis. In the present study, a case of successful oral desensitization with crizotinib following development of crizotinib_induced hepatitis is presented.

\section{Case report}

A 51-year-old Japanese woman with no history of smoking received crizotinib (250 $\mathrm{mg}$ twice daily) as second-line treatment for relapse of resected lung adenocarcinoma following progression while on first-line chemotherapy with carboplatin/pemetrexed. On day 2, crizotinib was discontinued due to abdominal pain, nausea and grade 3 diarrhea. The symptoms improved in 3 days and crizotinib was re-introduced at $250 \mathrm{mg}$ once daily on day 7 , with dexamethasone $3 \mathrm{mg}$ daily for nausea. Although there was no abdominal pain or diarrhea, the patient developed fever and nausea on day 15. The serum aspartate aminotransferase (AST) and alanine aminotransferase (ALT) levels increased and crizotinib was again discontinued on day 16. The peak of AST was $437 \mathrm{IU} / 1$ on day 18 and that of ALT 1,096 IU/1 on day 19 (Fig. 1). The level of alkaline phosphatase did not increase, whereas $\gamma$-glutamyltransferase and total bilirubin increased to grade 2 toxicity levels. Hepatocellular injury was suspected and contrast-enhanced computed tomography and ultrasonography did not reveal other causes, whereas hepatitis A, B or C was excluded. The patient's serum tested negative for polymerase chain reaction of Epstein-Barr virus and cytomegalovirus. The symptoms and blood test abnormalities completely resolved without increase of steroids after 1 month.

After carboplatin/pemetrexed rechallenge as third-line treatment and docetaxel as fourth-line treatment, the disease progressed and the patient was started on crizotinib at $50 \mathrm{mg}$ 
daily, as there was no alternative treatment for lung cancer. The contents of crizotinib capsules were dissolved in sterile water and diluted to the desired concentrations. The patient was also administered $2 \mathrm{mg}$ of betamethasone for nausea, as she developed brain metastasis and was treated with whole-brain radiotherapy. Crizotinib was gradually increased and grade 1 hepatotoxicity developed on day 12. Ursodeoxycholic acid and glycyrrhizic acid were started thereafter, and no hepatotoxicity was observed (Fig. 2). All the metastatic lymph nodes shrank and the patient achieved partial response (Fig. 3). There was disease progression after 5 months of treatment, and crizotinib was continued beyond progression. However, the treatment beyond progression did not improve her condition and the patient succumbed to respiratory failure with carcinomatous pleurisy.

\section{Discussion}

The detection of ALK rearrangement in non-small-cell lung cancer (NSCLC) prompted the development of ALK inhibitors. Crizotinib is the first inhibitor of ALK, ROS1 and MET. Although there are several ALK inhibitors, one of which, alectinib, appears to be more efficacious and less toxic compared with crizotinib (3), crizotinib is not only an ALK inhibitor, but also acts against ROS1 (4). However, is important to establish a method of re-administration following the development of crizotinib-induced adverse effects.

One of the most common adverse effects of crizotinib is hepatotoxicity. Grade 3-4 ALT elevations occur in $\sim 15 \%$ of NSCLC patients with ALK rearrangement mutations $(2,5)$. Three cases of crizotinib-induced hepatitis have been reported, all of which occurred within a few months after the introduction of crizotinib (6-8). In one of those cases, rechallenge with half-dose crizotinib failed due to recurrence of hepatitis (6). Similarly, in the present case, dose-independent hepatotoxicity suggested that the underlying mechanism was partly an allergic reaction to crizotinib or its metabolites; however, the precise mechanism underlying crizotinib-induced liver toxicity has not been fully elucidated. Although successful desensitization with crizotinib following crizotinib-induced urticarial rash was reported (9), there was no report of desensitization to ALK inhibitors following drug-induced liver injury. In the present case, oral steroids were used together during oral desensitization, which may have contributed to the treatment success. However, common dose reduction with oral steroids following crizotinib-induced hepatitis did not improve the hepatitis; therefore, oral desensitization may be considered as a viable option following crizotinib-induced hepatitis. Drug-induced liver injury is generally associated with type 4 hypersensitivity reactions; the fact that crizotinib desensitization overcame hepatitis suggested the involvement of type 1 hypersensitivity.

Ceritinib and alectinib are also approved ALK inhibitors; however, since they were not approved at that time, crizotinib desensitization was attempted instead. A previous case report reported successful treatment with ceritinib following crizotinib-induced hepatitis (8). Therefore, these novel ALK inhibitors may be additional options for the management of crizotinib-induced hepatitis.

While the progression-free survival (PFS) of crizotinib as first-line treatment is $\sim 11$ months, its PFS as second-line

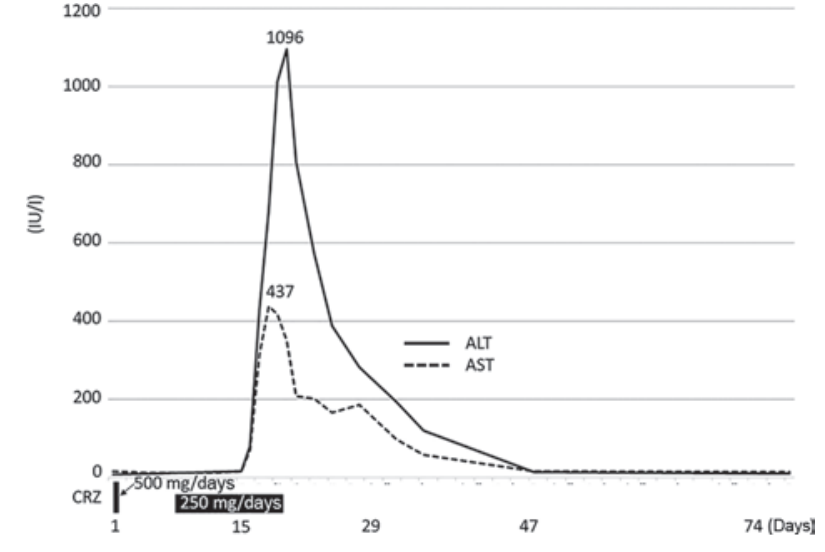

Figure 1. Clinical course of the patient treated with crizotinib (CRZ) as second-line therapy. ALT, alanine aminotransferase; AST, aspartate aminotransferase.

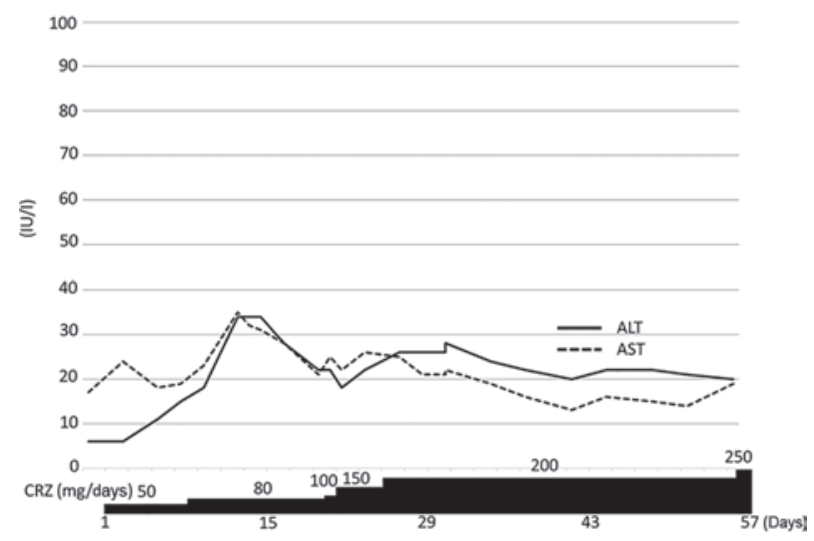

Figure 2. Clinical course of the patient undergoing crizotinib (CRZ) desensitization as fifth-line therapy. ALT, alanine aminotransferase; AST, aspartate aminotransferase.
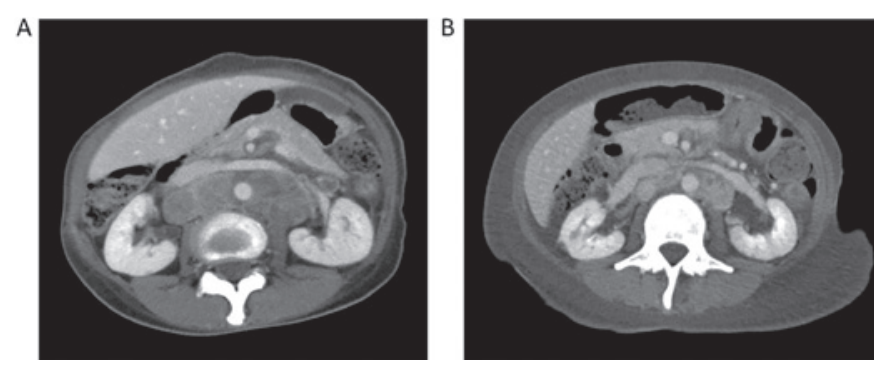

Figure 3. (A) Computed tomography (CT) scan prior to desensitization with crizotinib treatment and (B) CT scan 1 month after starting crizotinib treatment, showing partial response of the tumor.

treatment is $\sim 8$ months $(2,5)$. The PFS in the present case was shorter compared with these previously reported results. The later crizotinib is administered, or the lower its dose, the shorter the PFS. The efficacy of crizotinib is optimal at a dose of $250 \mathrm{mg}$ twice daily. A recent study on crizotinib pharmacokinetics revealed that crizotinib at a starting dose appeared to be effective and tolerable, regardless of race, age, sex, hepatic function, or mild to moderate renal impairment (10). Since the hepatitis in the present case was not dose-dependent, the crizotinib dose was increased to the greater extent possible. 
In conclusion, our case suggests that oral desensitization with crizotinib may be a viable alternative option in cases of crizotinib-induced hepatitis.

\section{References}

1. Kohno T, Nakaoku T, Tsuta K, Tsuchihara K, Matsumoto S, Yoh K and Goto K: Beyond ALK-RET, ROS1 and other oncogene fusions in lung cancer. Transl Lung Cancer Res 4: 156-164, 2015.

2. Solomon BJ, Mok T, Kim DW, Wu YL, Nakagawa K, Mekhail T, Felip E, Cappuzzo F, Paolini J, Usari T, et al: First-line crizotinib versus chemotherapy in ALK-positive lung cancer. N Engl J Med 371: 2167-2177, 2014.

3. Seto T, Kiura K, Nishio M, Nakagawa K, Maemondo M, Inoue A, Hida T, Yamamoto N, Yoshioka H, Harada M, et al: CH5424802 (RO5424802) for patients with ALK-rearranged advanced non-small-cell lung cancer (AF-001JP study): A single-arm, open-label, phase 1-2 study. Lancet Oncol 14: 590-598, 2013.

4. Shaw AT, Ou SH, Bang YJ, Camidge DR, Solomon BJ, Salgia R, Riely GJ, Varella-Garcia M, Shapiro GI, Costa DB, et al: Crizotinib in ROS1-rearranged non-small-cell lung cancer. N Engl J Med 371: 1963-1971, 2014.
5. Shaw AT, Kim DW, Nakagawa K, Seto T, Crinó L, Ahn MJ, De Pas T, Besse B, Solomon BJ, Blackhall F, et al: Crizotinib versus chemotherapy in advanced ALK-positive lung cancer. N Engl J Med 368: 2385-2394, 2013.

6. Ripault MP, Pinzani V, Fayolle V, Pageaux GP and Larrey D: Crizotinib-induced acute hepatitis: First case with relapse after reintroduction with reduced dose. Clin Res Hepatol Gastroenterol 37: e21-e23, 2013.

7. Sato Y, Fujimoto D, Shibata Y, Seo R, Suginoshita Y, Imai Y and Tomii K: Fulminant hepatitis following crizotinib administration for ALK-positive non-small-cell lung carcinoma. Jpn J Clin Oncol 44: 872-875, 2014.

8. Sassier M, Mennecier B, Gschwend A, Rein M, Coquerel A, Humbert X, Alexandre J, Fedrizzi S and Gervais R: Successful treatment with ceritinib after crizotinib induced hepatitis. Lung Cancer 95: 15-16, 2016.

9. Awad MM, Lax TP, Slawski BR and Shaw AT: Successful desensitization of two patients with ALK-positive lung cancer and hypersensitivity to crizotinib. J Thorac Oncol 9: 1726-1728, 2014.

10. Wang E, Nickens DJ, Bello A, Khosravan R, Amantea M, Wilner KD, Parivar K and Tan W: Clinical implications of the pharmacokinetics of crizotinib in populations of patients with non-small cell lung cancer. Clin Cancer Res 22: 5722-5728, 2016. 